\section{Pacific Northwest}

National Laboratory

Operated by Battelle for the

U.S. Department of Energy

\title{
High Resolution Imaging of Vadose Zone Transport Using Crosswell Radar and Seismic Methods
}

\author{
Ernest L. Majer \\ John E. Peterson \\ Kenneth H. Williams \\ Thomas M. Daley \\ Lawrence Berkeley National Laboratory \\ Glendon W. Gee \\ Vadose Zone Transport Field Study Project Manager \\ Pacific Northwest National Laboratory
}

September 1, 2000

Prepared for the U.S. Department of Energy under Contract DE-AC06-76RL01830 


\section{DISCLAIMER}

This report was prepared as an account of work sponsored by an agency of the United States Government. Neither the United States Government nor any agency thereof, nor Battelle Memorial Institute, nor any of their employees, makes any warranty, express or implied, or assumes any legal liability or responsibility for the accuracy, completeness, or usefulness of any information, apparatus, product, or process disclosed, or represents that its use would not infringe privately owned rights. Reference herein to any specific commercial product, process, or service by trade name, trademark, manufacturer, or otherwise does not necessarily constitute or imply its endorsement, recommendation, or favoring by the United States Government or any agency thereof, or Battelle Memorial Institute. The views and opinions of authors expressed herein do not necessarily state or reflect those of the United States Government or any agency thereof.

PACIFIC NORTHWEST NATIONAL LABORATORY

operated by

BATTELLE

for the

UNITED STATES DEPARTMENT OF ENERGY

under Contract DE-AC06-76RL01830 


\title{
High Resolution Imaging of Vadose Zone Transport Using Crosswell Radar and Seismic Methods
}

\author{
Ernest L. Majer \\ John E. Peterson \\ Kenneth H. Williams \\ Thomas M. Daley \\ Lawrence Berkeley National Laboratory
}

Glendon W. Gee

Vadose Zone Transport Field Study Project Manager

Pacific Northwest National Laboratory

Sept. 1, 2000

Prepared for the U.S. Department of Energy

under Contract DE-AC06-76RL01830

Pacific Northwest National Laboratory

Richland, Washington 99352 


\section{Contents}

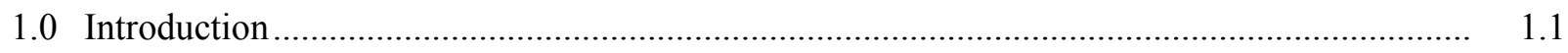

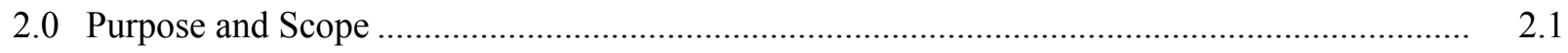

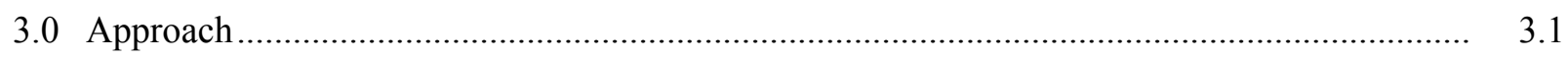

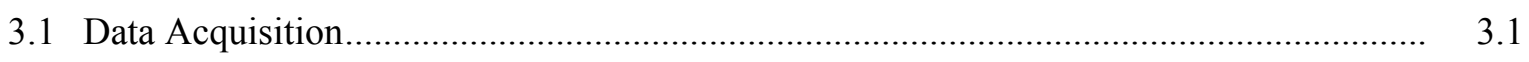

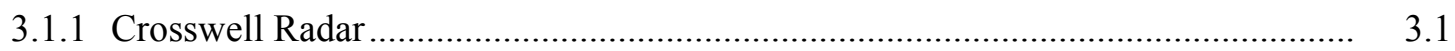

3.1.2 Crosswell Seismic ........................................................................................ 3.3

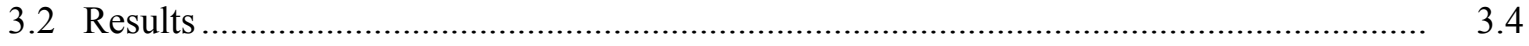

3.2.1 Ground Penetrating Radar....................................................................... 3.4

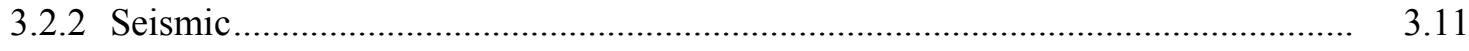

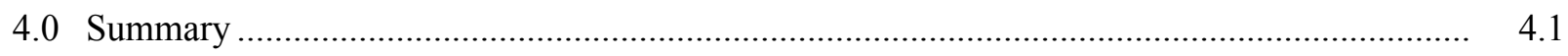

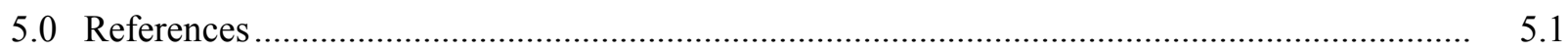

\section{Figures}

3.1. Well Array at the Sisson and Lu Test Site in the 200 East Area at Hanford......................... 3.2

3.2. Cut-Way View of Test Site Showing Well Layout ............................................................ 3.3

3.3. Radar Results from the Pre Injection Tests Between the Different Well Pairs...................... 3.5

3.4. The Top Figure Shows the Close Comparison Between the Moisture Estimation from Radar Data and the Estimation from Neutron Probe Data ................................................ 3.6

3.5. Moisture Content Derived from Radar Data Between Wells X2 and X3 Compared to Moisture Content Data in the same Region Derived from Neutron Probe Data.................... 3.8

3.6. Changes in Water Content After the First Water Injection .................................................. 3.9

3.7. Changes in Moisture Content After the Second Injection................................................... 3.10

3.8. Changes in Moisture Injection During the Fifth Injection ............................................... 3.12

3.9. Change in Water Content Two Weeks After the Fifth Injection......................................... 3.13

3.10. The Definition of Structure from Radar and Seismic; Note the Much More Detail in Structure Derived from the Seismic .............................................................................. 3.14

3.11. The Frequency Response as a Function of Time for the Seismic Source Used in the Large Offset Wells

3.12. Example of Seismic Data at $19 \mathrm{~m}$ Through the Upper Vadose Zone Using a Seismic Source in the Range of 50 to 300 Hertz 


\subsection{Introduction}

Although borehole and outcrops provide some sampling, there is a critical need to provide volumetric information between point measurements. For example, there is a need for information on heterogeneities at scales ranging from the centimeter to $10 \mathrm{~s}$ of meters, as these features can alter contaminant transport significantly. At Hanford, heterogeneities of interest can range from localized phenomena, such as silt or gravel lenses, fractures, and clastic dikes, to large-scale lithologic discontinuities. These features have been suspected of leading to funneling and fingering, additional physical mechanisms that could alter and possibly accelerate the transport of contaminants to underlying groundwater. It has also been observed from the studies to date that over relatively short distances, there are heterogeneities in the physical structure of the porous medium and structural differences between repacked soil cores and the field site from which the materials initially came. Crosswell geophysical measurements are one means to provide this information.

Understanding of contaminant migration through the vadose zone has not only been hampered by inadequate conceptual models but has suffered from inadequate monitoring technologies. In the past, contaminant plumes at Hanford have most often been mapped with gross and spectral gamma logging tools. Migration was documented by observing changes in gamma logs that failed to fully describe the contaminant plume since the dominant gamma emitters (e.g., $\left.{ }^{137} \mathrm{Cs},{ }^{90} \mathrm{Sr}\right)$ are reactive and hence retarded in Hanford sediments while non-reactive contaminants, such as technetium, tritium, and nitrate, move readily with the water. The inability to track highly mobile species through the vadose zone highlights an important need, the need for methods other than gamma logging to describe the complete vadose-zone plume and to determine processes controlling accelerated contamination of groundwater at Hanford.

Recent characterization efforts in the T and SX tank farms have relied on core sampling techniques (Freeman-Pollard et al. 1994; Myers et al. 1998). Analysis of cores taken from the vadose zone (i.e., soil surface to water table) has been useful in identifying localized zones of contamination. Unfortunately, these analyses are sparse (limited to a few boreholes) and extremely expensive. Without more coring, it will be difficult to clearly identify the extent of the contamination plume at a given location in the heterogeneous vadose zone at Hanford waste sites. Furthermore, the dilemma is cost, time, and practicality of such a characterization effort. Core samples taken from the SX tank farm have exceeded $10^{8} \mathrm{pCi} / \mathrm{g}$ (Raymond and Shdo 1966). The high levels of radioactivity increase drilling and sample costs as well as analysis time. The cost of drilling and core analysis for the SX tank farm has exceeded \$1M per borehole for sampling in the T and SX tank farms. While some of these costs may be reduced in the future, it also takes months to complete the analysis (LMHC 1999), when answers are needed today. In addition, these localized measurements, while providing useful information on present distribution, are of limited use in predicting future migration patterns. It is apparent that improved characterization and modeling methods that can reduce costs, shorten the time for analysis, and provide reliable estimates of vadose zone contaminant plumes at the Hanford Site are desperately needed (DOE 1998). The crossborehole methods may possibly provide a lower cost alternative as well as increased spatial and temporal sampling.

The main questions addressed with the crosswell methods are:

- What parts of the vadose zone-groundwater system control flow geometry? 
- What physics control flow and transport in unconsolidated soils of the vadose zone?

- What is the optimum suite of field tests and laboratory studies to provide information for predicting flow and transport behavior?

- How can the information obtained during site characterization be used for building confidence in predictive numerical models?

A fully developed application of geophysics at Hanford should enable contaminant distributions to be located. Questions addressed were the sensitivity, resolution, and accuracy of the crosswell methods to derive the spatial and temporal distribution of properties controlling transport and contaminant distribution between and away from boreholes and the surface. Implicit in this activity is that geophysical methods will be used to extrapolate and extend measurements made at the point scale to the volumetric scale. Also implied will be that the methods will be applied to derive static as well as dynamic properties in order to define flow processes as well as intensive properties. In a broad sense, the research focuses on the capability of the geophysical methods to define as well as separate the natural complexity and heterogeneity of the subsurface from that created by the contaminants.

Overall, there are two broad hypotheses being addressed in the crosswell geophysical work:

(1) Geophysical methods can identify physical and chemical heterogeneity controlling contaminant transport at a meaningful scale.

(2) Geophysical methods have the sensitivity to directly or indirectly detect the location of the fluids and/or contaminants at a practical concentration (i.e., the subsurface has been altered from its natural state enough to create anomalies that can be detected, i.e., mechanical, electrical, thermal, etc.).

Examples of specific applications are

(1) Change in moisture content in the vadose zone

(2) Degree of continuity/thickness of lithologic units in the vadose zone (Hanford sands, plio-pleistocene caliche, upper Ringold sands, Ringold gravels, etc.

(3) Location and distribution of heterogeneities within the lithology (sills, clastic dikes, fractures/faults, fracture orientation/density etc.)

(4) Matrix and fracture properties of units (porosity, grain size distribution, moisture distribution, mineral composition, etc.).

(5) Location and extent of contaminant plumes that may have an anomalous chemical or physical signature (precipitation/alteration products, secondary deposition, etc.)

(6) Location of "fast paths" affecting transport (natural and contaminant induced). 


\subsection{Purpose and Scope}

The primary purpose of the crosswell radar and seismic imaging is to provide detailed information on the lithology and structure ( $25 \mathrm{~cm}$ or less resolution) as well as provide the same level of detail on the location of the fluid transport. A second purpose is to evaluate these methods and/or modify the methods to determine their use at the tank-farm scale. The radar methods were applied in a time-lapse sense to determine changes in the moisture content; thus there was repeated measurements at the same sites. The seismic measurements were designed to examine structural and lithologic heterogeneity, and thus were used only once. We assumed before we applied the seismic measurements that they would be less sensitive to fluid content; however, as will be seen below, the seismic measurements may have high enough frequency content and resolution to provide valuable independent information from the electrical measurements.

As was stated in the initial test plan, a common goal among core projects is to collect field data and develop conceptual models of vadose-zone flow and transport. Also, the capability to identify changes from the baseline also demands the identification of advanced technologies capable, not only of using the existing infrastructure to detect contaminants, but also of locating in situ the high-risk, often difficult-todetect contaminants using surrogate measurements. A major challenge lies in extrapolating results over multiple spatial scales and from one site to the next. In heterogeneous environments, such extrapolation can only be accomplished after the spatial-scale dependence of flow and transport properties and known. Thus, the crosswell seismic and radar were designed to address these fundamental goals as well as the more practical goals of use some day at the tank-farm scale. 


\subsection{Approach}

Figure 3.1 shows a plan view of the well configuration at the Sisson and Lu test site with the wells marked as " $x$ " as the wells used for the crosswell radar and seismic studies. These wells were located based on the past experience of the most likely location of flow during the new injection experiments. Figure 3.2 shows a cut-away view of the test site and well layout with a conceptual diagram of how flow took place during the last experiments. In the previous experiments, an injection well was placed in the center of the well field and was surrounded by 32 observation wells. The wells were constructed from three 20 -ft sections and one 5 -ft section of 6-in.-diameter schedule 40 steel casing. The sections were welded together to form watertight joints reinforced with four steel straps welded symmetrically around the casing. During installation, the 5-ft section of casing was driven into the soil, and then the $20-\mathrm{ft}$ section was welded on, and the driving continued until the top of the casing was beyond the reach of the drive hammer. Soils with the casing (drill cuttings) were removed by advancing $20 \mathrm{ft}$ with a rotary by using air as a drilling fluid. Cuttings were blown out of the casing and collected near the point of drilling. Samples were collected of these cuttings and stored in containers, and later selected samples were analyzed for hydraulic properties (Rockhold et al. 1999). In the present case, the X wells were PVC cased (2-in. I.D.) and emplaced with CPT technology. Then crosswell methods were used to monitor the simulated leak-injections of 4000-L increments over a 6-week period. The crosswell data were combined with the neutron logging results in the steel-cased wells. The measurement focus was to determine the state variables controlling water movement (i.e., water content, physical heterogeneities, and, if possible, water potential, chemical concentrations and temperature). In the new configuration, the $\mathrm{X}$ wells were PVC cases (2-in. I.D.) and were emplaced with cone-penetrometer technology.

\subsection{Data Acquisition}

\subsubsection{Crosswell Radar}

The ground penetrating radar (GPR) work at Hanford consisted of repeated crosswell tomographic datasets being collected between the following six possible well pairs at the Sisson-Lu site: X1-X2, X2$\mathrm{X} 3, \mathrm{X} 3-\mathrm{X} 4$. X1-X2, X1-X3, and X2-X4. Four data-collection visits were made to the site with three of the visits consisting of exactly the same datasets being collected. These include the May $25^{\text {th }}$ (PRE) visit that constituted the precursory (i.e., baseline) dataset, followed by the June $13^{\text {th }}$ (POST1) and July $14^{\text {th }}$ (POST3) that consisted of identical datasets to those of the baseline. All three of the visits were collected using the Sensors \& Software, Inc. PulseEKKO 100 GPR system using the 200-MHz center frequency antennas. The step size for data collection between well pairs X1-X2, X2-X3, and X3-X4 was 0.125 m. The step size for data collection between well pairs X1-X4, X1-X3, and X2-X4 was $0.25 \mathrm{~m}$. Additionally, a fourth data-collection visit was made on June $28^{\text {th }}$ (POST2) that comprised nearly continuous data acquisition during an injection between well pair X1-X2. This was done in an attempt to image any change in moisture distribution over the duration of a single injection. Specifically, data were acquired the evening before infiltration started on June $28^{\text {th }}$, followed by data acquired at discreet intervals after approximately 150 gal, 400 gal, and 900 gal were released. Additionally, the POST2 visit also included data collection between well pairs X1-X3 and X2-X4. It should be noted that the PRE data set was collected approximately 1 week before beginning infiltration at the site. The POST1 and POST3 data-collection visits occurred approximately 1 week and 2 weeks, respectively, after their associated infiltration pulses $(06 / 08 / 00$ and $07 / 28 / 00)$. 


\section{Legend}

adv.Tensiometer Nest (Augered)

- Adv. Tensiom eter Nest (CPT)

- Cross-Borehole Access

$\$$ ERT Array

- New Injection Point

Subsur face Radiation Zone

- Split-spocn Cores

O Steel-cased Well

Figure 3.1. Well Array at the Sisson and Lu Test Site in the 200 East Area at Hanford. The shaded area beteen X1, X2, X3, and X4 was the target area for the crosswell. 


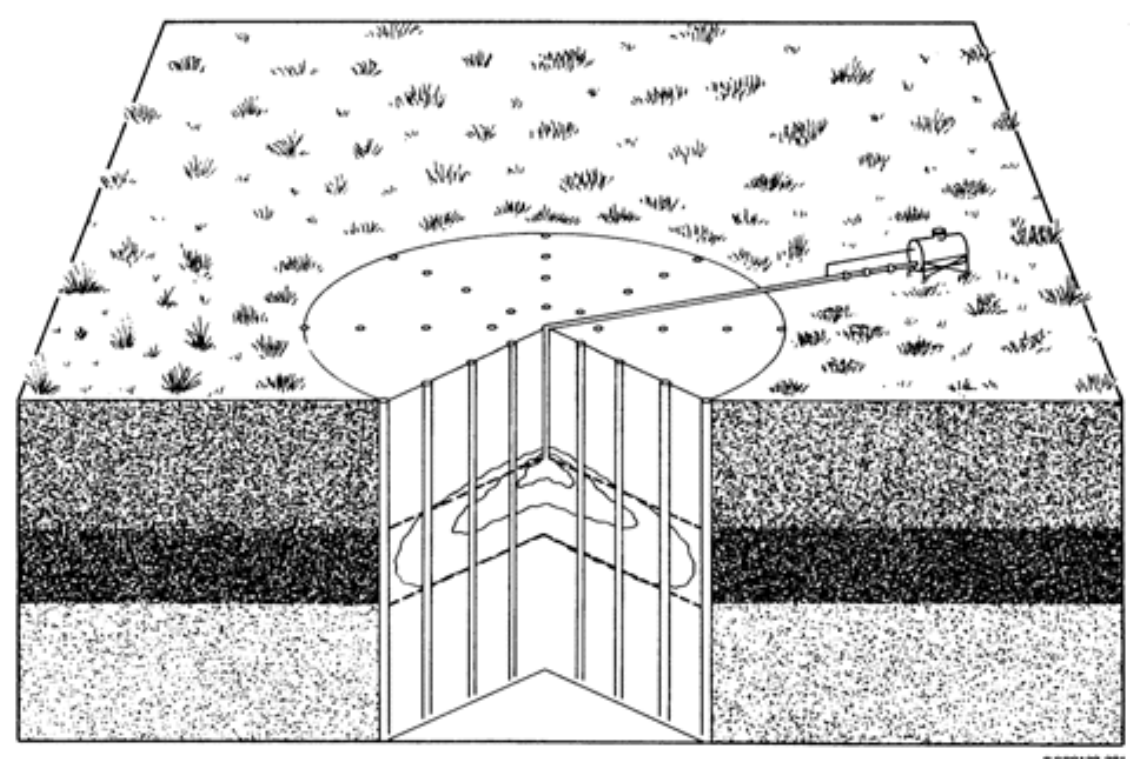

Figure 3.2. Cut-Way View of Test Site Showing Well Layout

\subsubsection{Crosswell Seismic}

The crosswell seismic was collected after all of the infiltration tests were completed. This was because the wells used for the crosswell seismic had to be filled with water (this would not have to be the case in the tank farm; it just made it easier in this case) to provide good seismic coupling in the small PVC cased wells. Because we did not know if the wells would leak, we did not want to have water into the formation during the infiltration tests. Until this experiment, it has been our experience that it is very difficult to collect high-resolution seismic data (in the kilohertz range) in a vadose zone geology. This is because partial saturation usually greatly attenuates seismic energy. In fact, until this experiment, we were not aware of any high-frequency seismic data collected at this scale in any vadose-zone environment. There were four different seismic crosswell sections obtained, three high resolution sections and one long offset section using a distant 6 -in. steel-cased hole for a source hole. The three high-resolution sections were collected by placing a 24-element hydrophone array in well X4, which was filled with water. A 1.5-in. diameter by 4-in.-long piezoelectric cylindrical seismic source was then used successively in wells X3, X2, and X1. The data were collected in a tomographic sense at 0.25 -m intervals for both source and receiver. The piezoelectric source put out energy from 1 to 10 kilohertz. The long offset section was obtained by leaving the hydrophone array in Well X4 and placing an orbital vibrator source in Well 2E-24-110, which was also filled with water, approximately19 $\mathrm{m}$ away from X4. The purpose of this was to see how far seismic energy could be transmitted in the vadose zone. The orbital vibrator is a much stronger source than the piezoelectric source, but puts out lower frequencies, in the 50 to 300 hertz range. Assuming that the resolution is on the order of $1 / 4$ wave length, and the velocities are on the order of $700 \mathrm{~m} / \mathrm{sec}$ (this is what we measured), then we were getting possible resolution of $10 \mathrm{~cm}$ for the piezoelectric data and $60 \mathrm{~cm}$ for the orbital source (assuming 300 hertz for the orbital source and 2000 hertz for the piezoelectric source). 


\subsection{Results}

\subsubsection{Ground Penetrating Radar}

Electromagnetic wave slownesses (the reciprocal of velocity) were estimated for this study using the travel times of the propagation waves and a straight-ray algebraic reconstruction inversion technique (Peterson et al. 1985). A velocity pixel dimension of $0.25 \times 0.25 \mathrm{~m}$ was used for the image inversion. Figure 3.3 shows the velocities obtained from the slowness values between all six well pairs collected before the infiltration tests.

This data set is used to delineate the stratigraphic layering in the vicinity of the tomographic profiles. The electromagnetic propagation velocity range observed on the tomograms of approximately 0.11 to $0.16 \mathrm{~m} / \mathrm{ns}$ is typical for unsaturated, unconsolidated sands.

The variation in velocity in unsaturated materials usually indicates variations in moistures or texture. The tomograms suggest the presence of six to seven distinct velocity layers, each continuous across the length of the tomogram and ranging in thickness from 0.25 to $3.5 \mathrm{~m}$. The layers alternate between higher and lower velocities with the shallowest layer having very low velocities $(<0.11 \mathrm{~m} / \mathrm{ns})$ and extending from the surface to about $3.0 \mathrm{~m}$ below ground surface (BGS). The next deeper layer is of higher velocity $(\sim 0.14 \mathrm{~m} / \mathrm{ns})$ and extends 3.0 to $3.5 \mathrm{~m}$ below this first layer to a depth of $\sim 6.5 \mathrm{~m}$. Some lateral velocity inhomogeneity is observed in this layer. The third layer consists of 0.25 to $0.50 \mathrm{~m}$ of low velocity material, which usually indicates a fine sand. While this layer is observed to be primarily flat, there appears to be some thickening or splitting of this layer near borehole X1. Another thin layer (Layer 4) 0.25 to $0.50 \mathrm{~m}$ thick, consisting of higher velocity material, suggests a more coarse-grain material. This layer has velocities just slightly higher than the layer below it and can be best seen in the X3-X2 tomogram. The next deeper layer (Layer 5) is approximately $3.0 \mathrm{~m}$ thick with similar velocities to those of Layer 2, suggesting that it may be made up of similar material. Layer 6 is similar to Layer 3 in thickness, though slightly thicker $(0.50$ to $0.75 \mathrm{~m})$, and velocity. Below this is the final (seventh) layer, which exhibits the highest velocities $(>0.16 \mathrm{~m} / \mathrm{ns})$. These seven layers extend across the entire set of radar profiles, exhibiting lateral continuity of at least four square meters.

The electromagnetic wave velocities $(v)$, obtained from the slowness estimates, can be converted to dielectric constant estimates $(\kappa)$ using $\kappa=\frac{c^{2}}{v^{2}}$ where $c$ is the velocity of electromagnetic waves through air. Dielectric constants in geologic materials range from approximately 3 to 25 . As the dielectric constant of air is 1 and water is 80 , water content will have the dominant effect on the dielectric constant of an unsaturated material. It is possible to convert the dielectric constant into estimates of water content using a variety of methods. A common method of conversion is through the use of the Topp's curve, which is an empirical relationship between the dielectric constant and water content determined in the laboratory (Topp 1980). The most direct and precise method is to correlate the field-scale dielectric constant estimates obtained from the tomograms near the wells with co-located neutron probe measurements of water content. The similarity of dielectric constant and moisture content responses is illustrated at Well X3, shown in Figure 3.4a. Figure 3.4b shows the dielectric constant and water-content values plotted against one another with the best-fit line and the Topps curve superimposed on top of the measurements. 

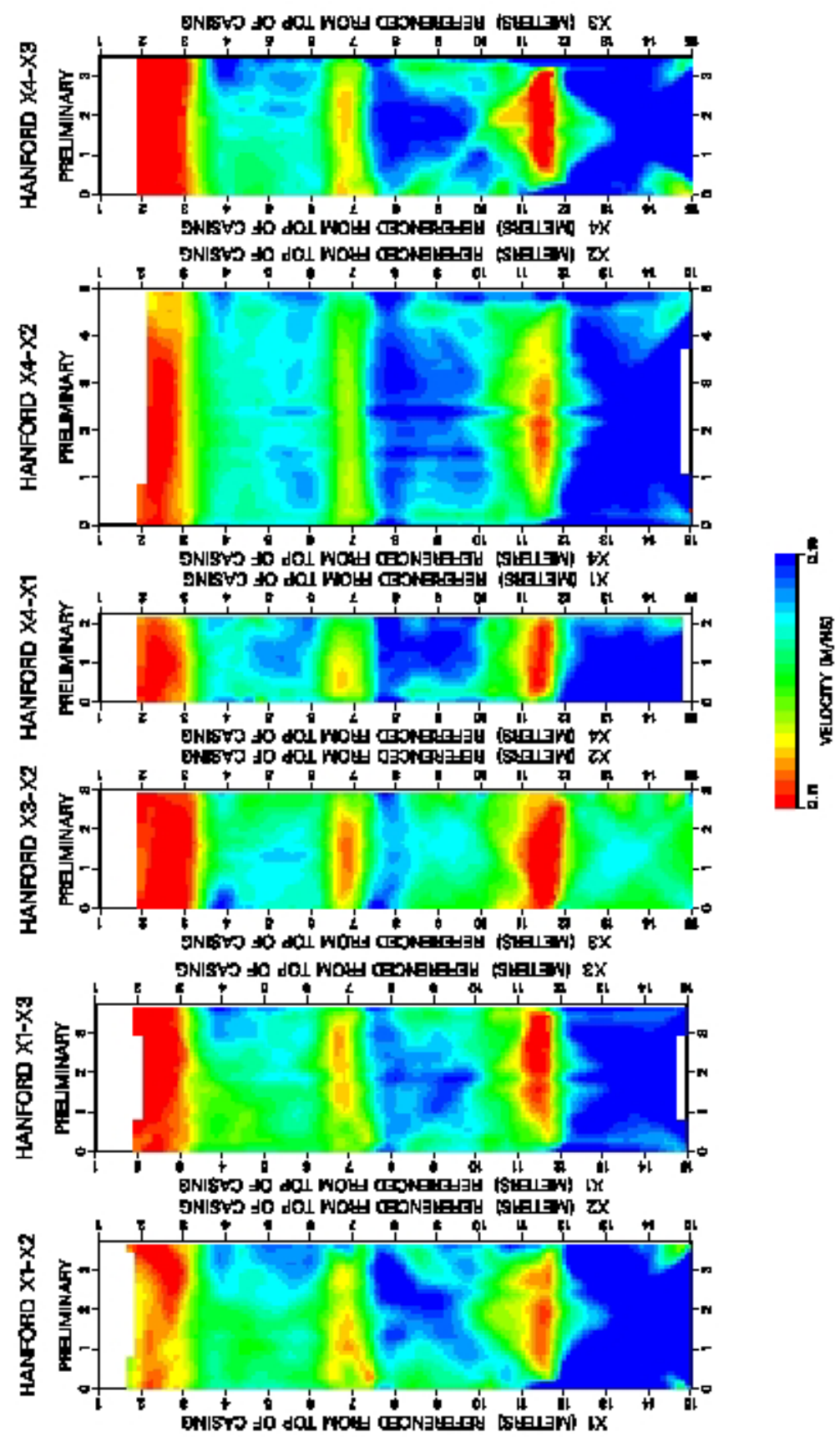

Figure 3.3. $\quad$ Radar Results from the Pre Injection Tests Between the Different Well Pairs 
HANFCRD $\times 3$

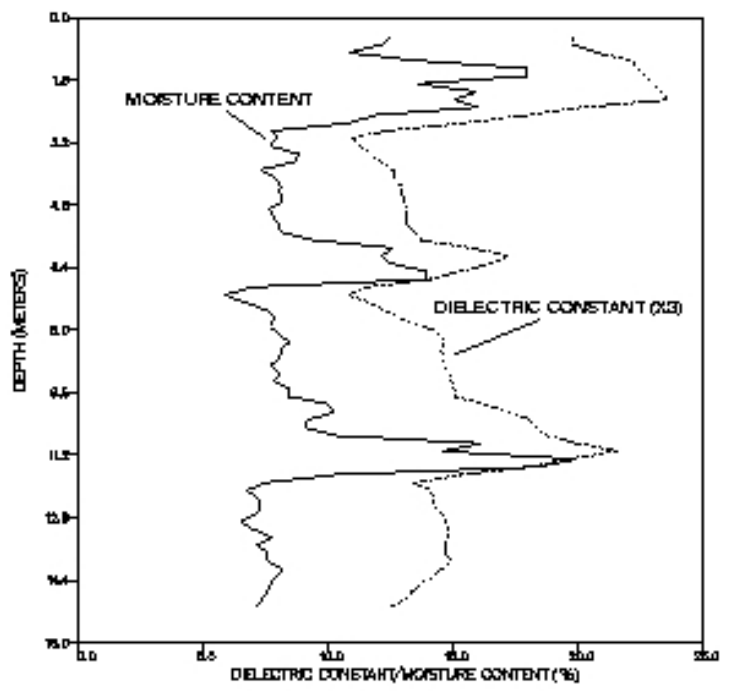

FIGURE 4A

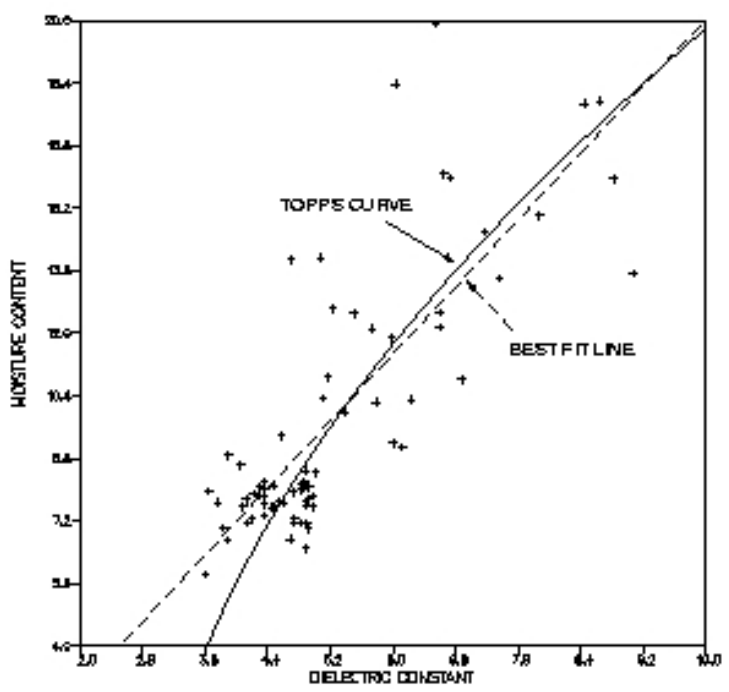

FGURE 4B

Figure 3.4. The Top Figure Shows the Close Comparison Between the Moisture Estimation from Radar Data and the Estimation from Neutron Probe Data. The bottom figure shows the fit of the data using the Topp's equation. 
The similarity of the field scale, site-specific dielectric constant-water content relationship to the labscale, empirically obtained "universal" Topp's relationship indicates the robusteness of radar techniques for moisture estimation in the vadose zone.

The dielectric constants obtained from the tomograms were converted to estimates of water content using the values of the site-specific petrophysical relationship. An example of water content estimates obtained in this manner is shown in Figure 3.5 using the X3-X2 tomogram.

The moisture-content estimates in Figure 3.5 are for the baseline case. Also shown in Figure 3.5 is the estimate of water content in using neutron probe data. One must remember that the neutron probe data are point measurements along the borehole (and not taken in the exact same boreholes). The data shown in Figure 3.5 from the neutron data are extrapolated (contoured) between the boreholes in contrast to the radar data, which are volumetric measurements.

By differencing the traveling times between the POST1 (acquired 1 week after the second injection) and the baseline measurements (collected in May) and inverting these differences, we obtain an estimate for the change in radar properties. Because the geology remains constant, the observed change in dielectric constant should indicate the change in moisture. These estimates can be converted to change in moisture content using the same site-specific petrophysical relationship discussed above. Figure 3.6 shows the changes in moisture content for three of the well pairs associated with POST1.

The results indicate that the greatest changes in moisture occur just above the low moisture zone at $6.5 \mathrm{~m}$ in depth (Layer 3) and just above the low moisture feature at $10 \mathrm{~m}$ in depth (Layer 6). In fact, there appear to be no changes in moisture (or retention in water content) below $10 \mathrm{~m}$. These data suggest that, at the time of this tomogram ( 2 weeks after Injection 1 and 1 week after Injection 2), only a small amount of water had flowed (or been retained) into the area sampled by the X4-X3 well pair, which is about $3.5 \mathrm{~m}$ laterally from the injection point. These changes in moisture content can be compared to the neutronprobe water-content values as illustrated in Figure 3.7. 


\section{BASELINE DATA}

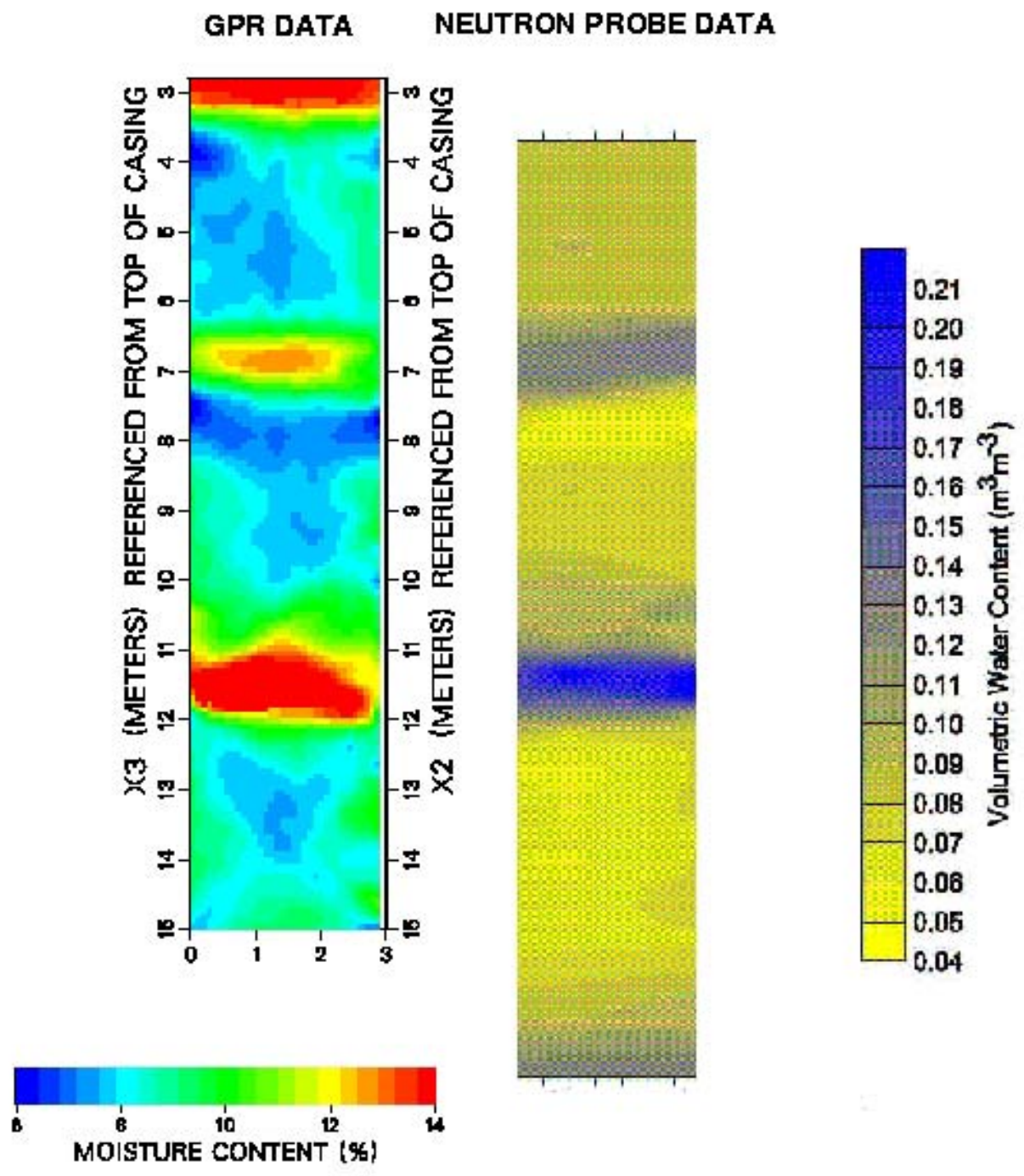

Figure 3.5. Moisture Content Derived from Radar Data Between Wells X2 and X3 Compared to Moisture Content Data in the same Region Derived from Neutron Probe Data 
POST1 MOISTURE CONTENT CHANGES

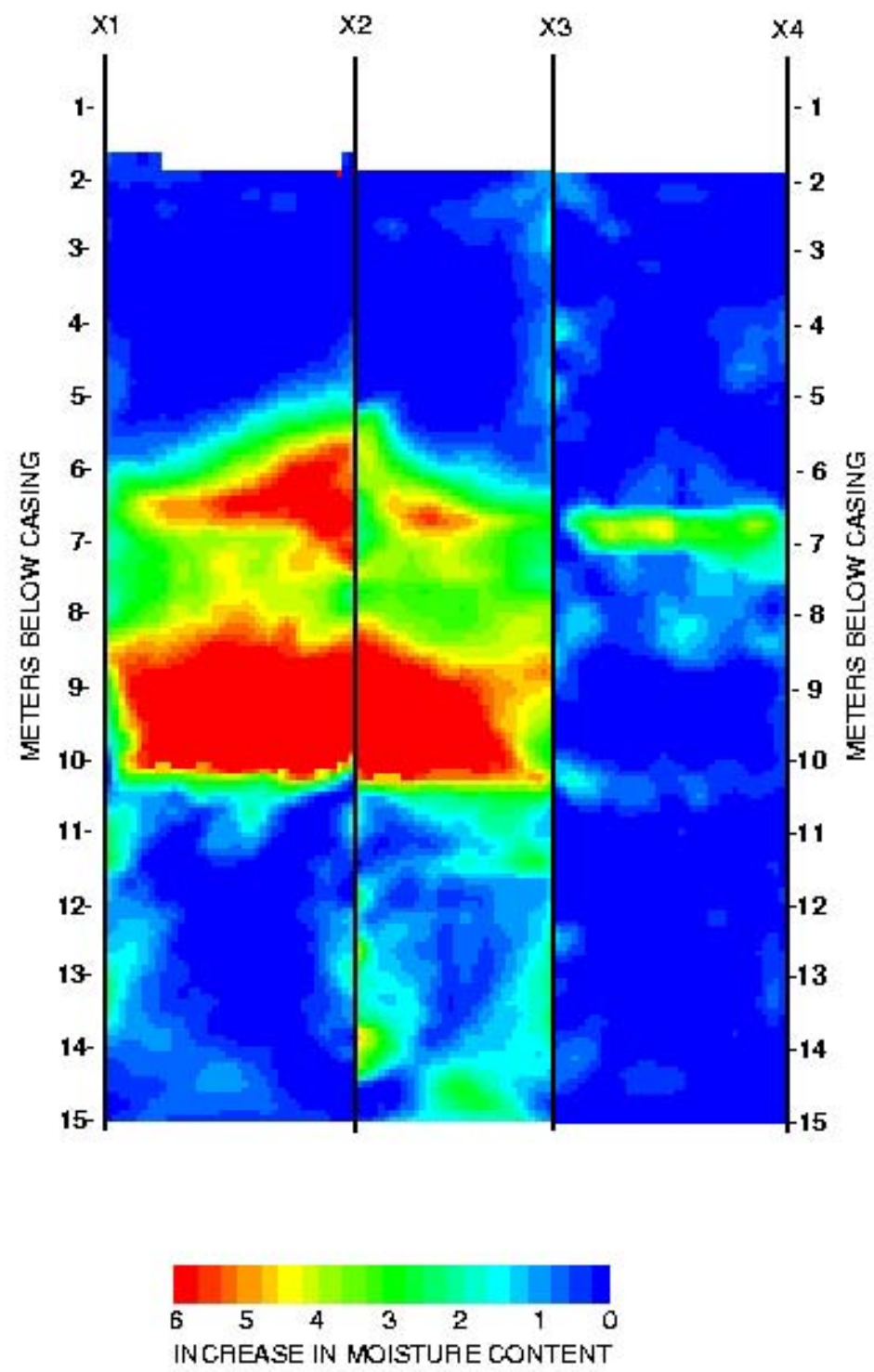

Figure 3.6. Changes in Water Content After the First Water Injection 


\section{POST INJECTION 2}

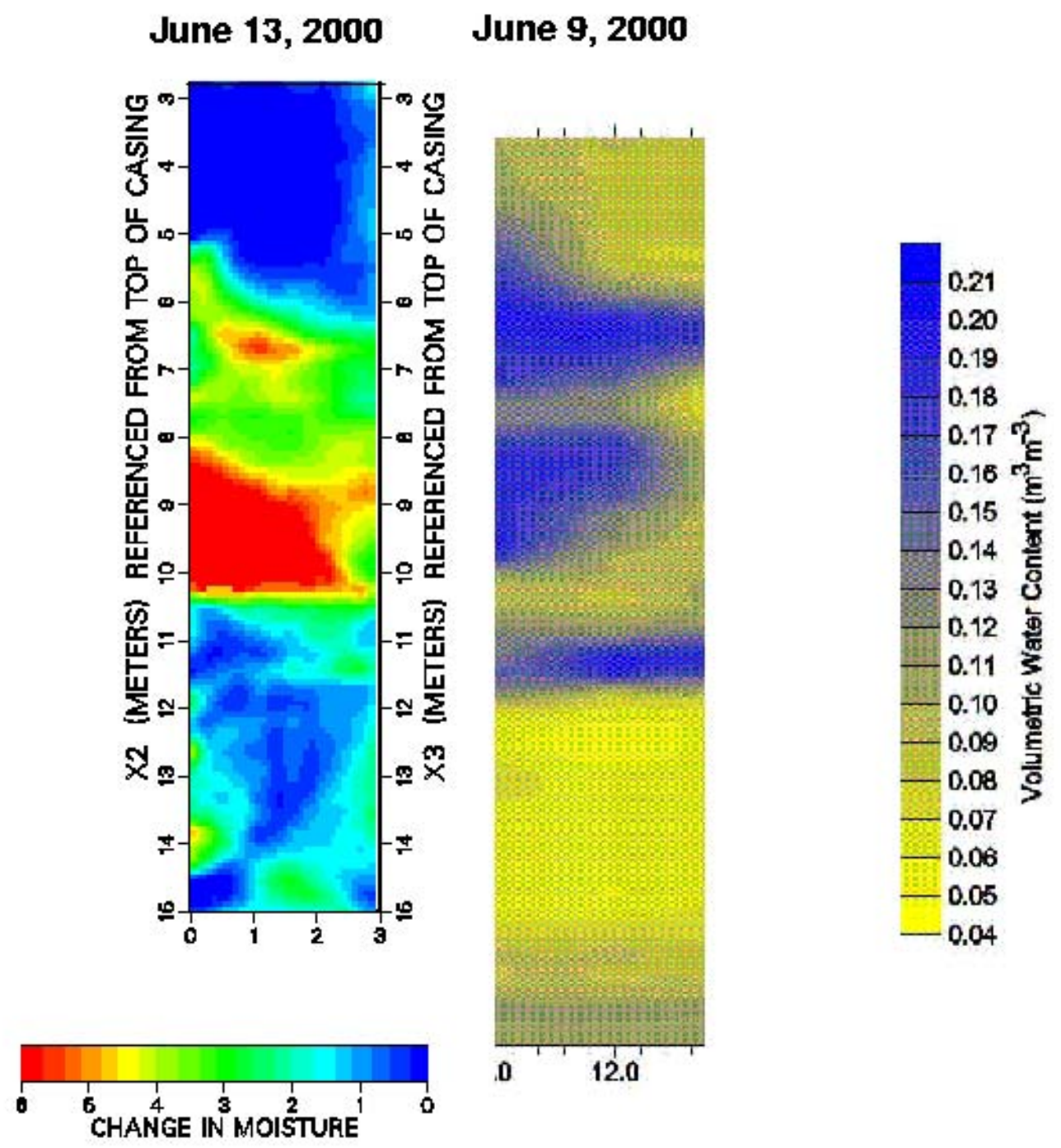

Figure 3.7. Changes in Moisture Content After the Second Injection

Although the neutron probe values are not "differenced" in this figure, a comparison of these values (POST1) with the neutron-probe data collected in May (Figure 3.5) indicate that moisture content changes detected by the neutron probe correspond to these changes indicated by the tomogram.

POST2 data were acquired during Injection 5 in an attempt to image any change in moisture distribution over the duration of a single injection. Data were acquired only between well pair X2-X1, the well pair closest to the injection point. Three complete data sets were acquired between these well pairs at discreet intervals after approximately 150, 400 and 900 gallons were released. The data were all 
subtracted from the baseline measurement acquired the afternoon before the Injection 5 release. After inverting these data, the slownesses were used to estimate changes in water content as described earlier. The change in moisture content, shown in Figure 3.8, suggests that during the time of active injection the fluid spreads horizontally above the Layer 3 low moisture zone and no change in moisture is observed in, or below, this layer during the time of injection.

POST3 data were acquired two weeks after Injection 5, the final injection of fluid. The data were differenced from the May baseline measure and the changes in moisture content are shown in Figure 3.9.

The regions of increased moisture above Layer 2 and Layer 5 are still observed. However, some moisture increase can now be observed below this level to about 12 m BGS.

\subsubsection{Seismic}

Although at this time all of the seismic data has not been processed the results to date are very surprising in their high quality, for both the close spacing X wells and the long offset work. Data acquired from the X1-X4 borehole pair has been processed and the travel times inverted for the seismic velocity structure. The same algorithm and parameters were used for this inversion of seismic data as were used for the radar data. Figure 3.10 shows the comparison of the radar and the seismic data estimates of the structure. 


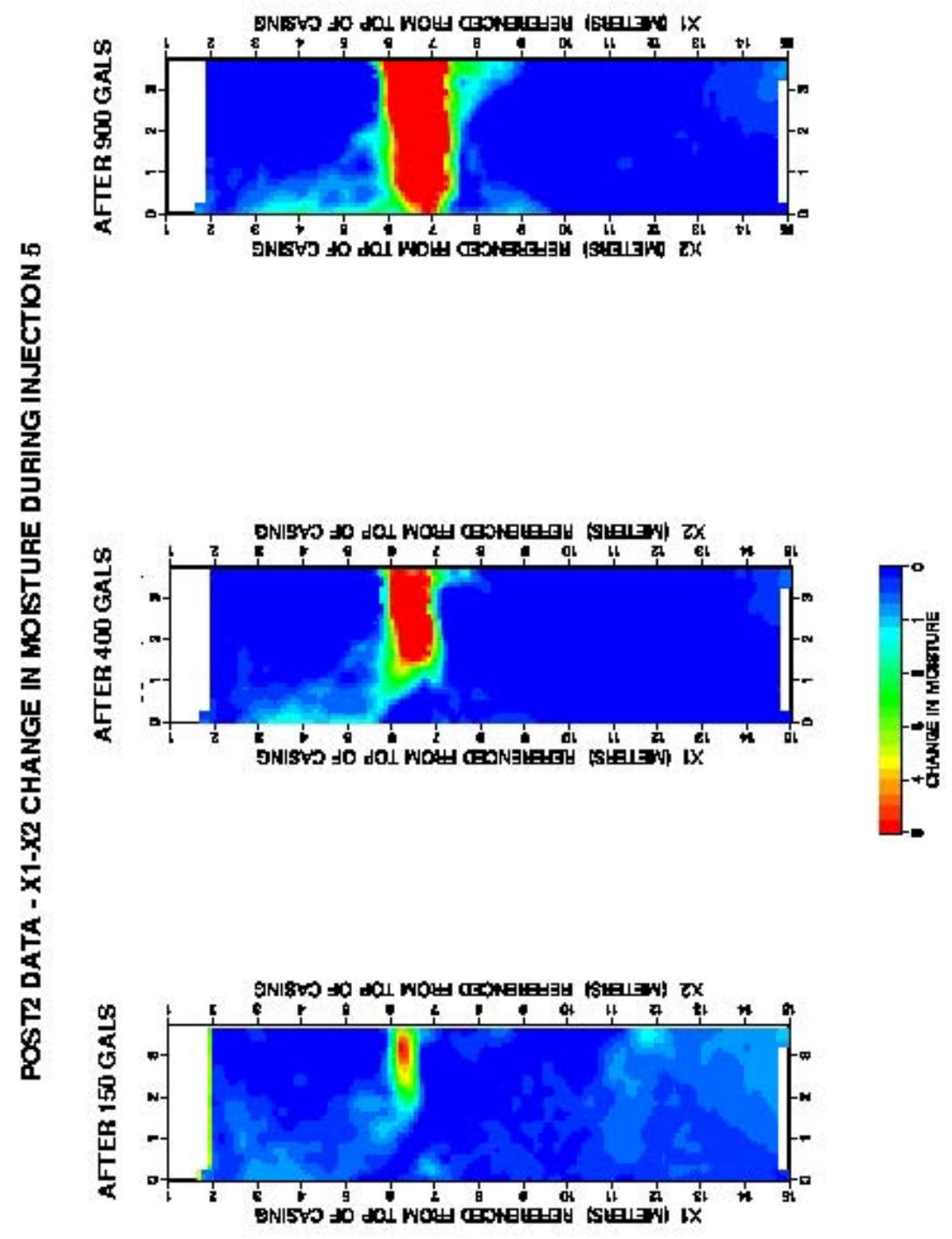

Figure 3.8. Changes in Moisture Injection During the Fifth Injection 
POST3 MOISTURE CONTENT CHANGES

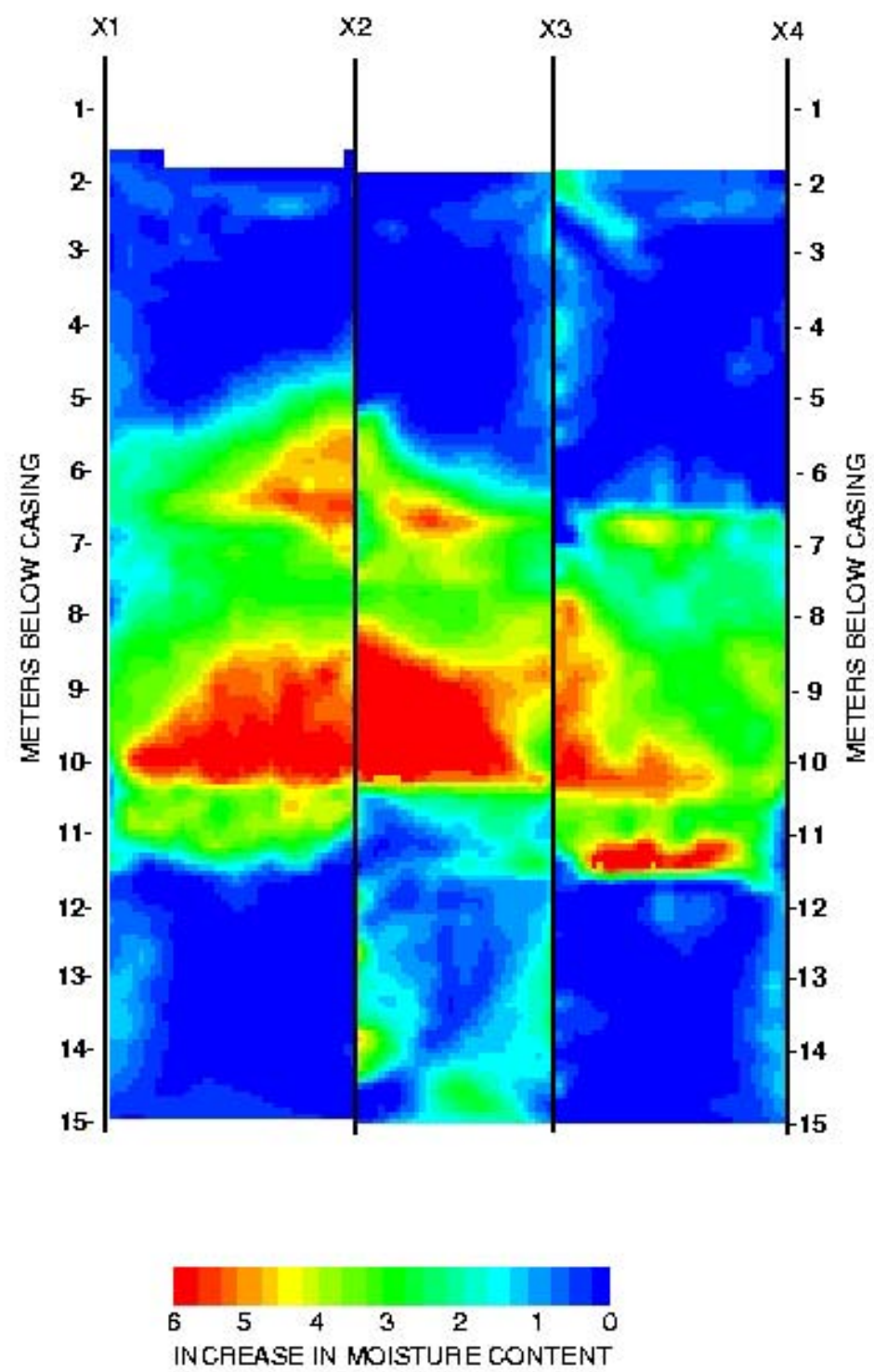

Figure 3.9. Change in Water Content Two Weeks After the Fifth Injection 
HANFORD $\times 4-X 1$

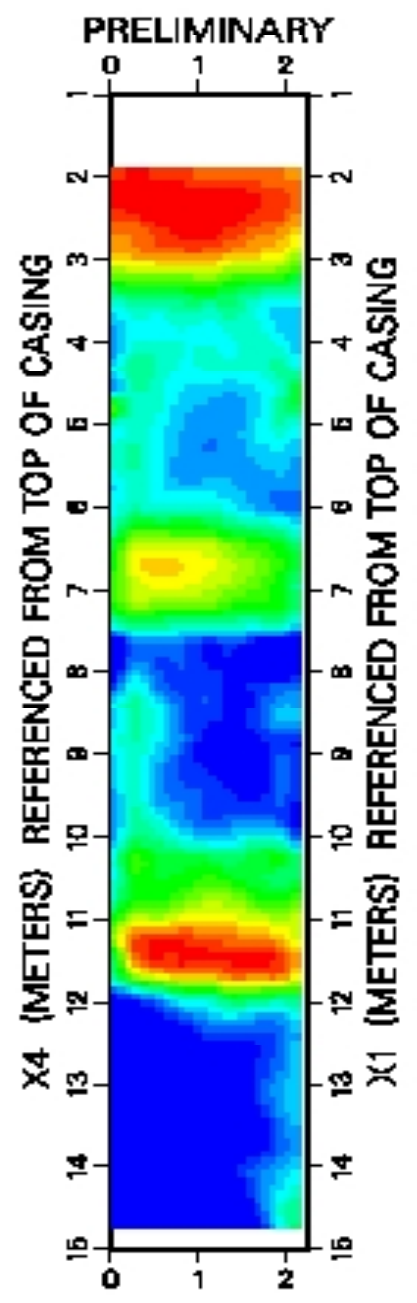

HANFORD $\times 1-\times 4$

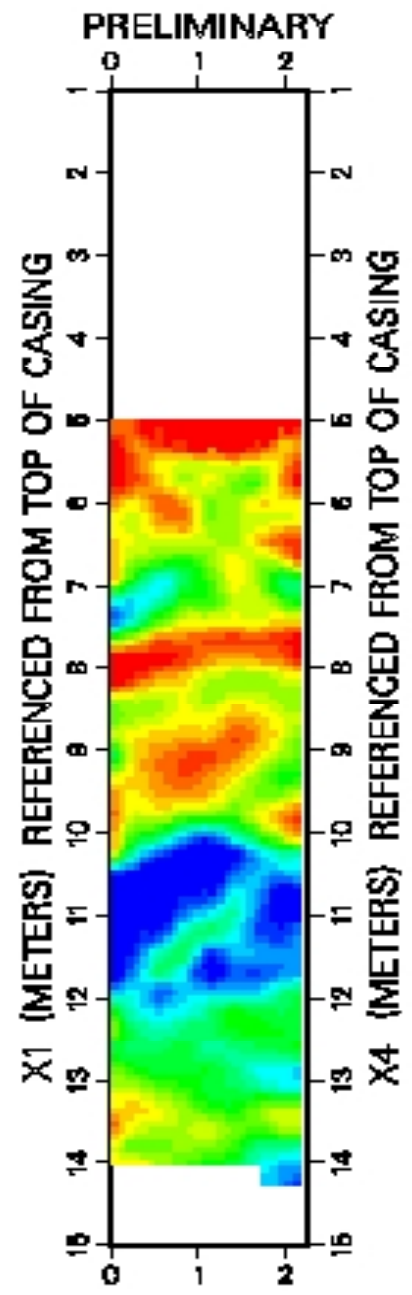

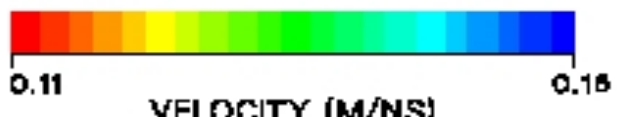

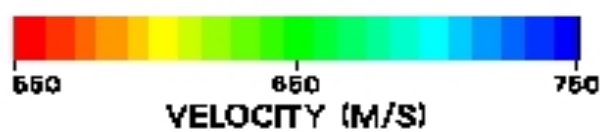

Figure 3.10. The Definition of Structure from Radar and Seismic; Note the Much More Detail in Structure Derived from the Seismic

Note that the seismic velocities are quite low, just above the velocity of air. The seismic velocities resolve the same stratigraphy as the radar-velocity estimates; however, the high-radar-velocity layers coincide with the low-seismic-velocity layers and visa versa. This is most likely because electromagnetic-wave velocities are high in air, while the acoustic-wave velocities are low in air. Therefore, in unsaturated material, the seismic waves should travel slowest in high-porosity material, and electromagnetic waves should travel fastest in high-porosity material. The velocity tomograms in Figure 3.10 appear to support this interpretation. 
Figure 3.11 and Figure 3.12 are data from the long-offset seismic test. These data are quite surprising also in that sesimic data of such high frequency can be propagated so far in this vadose zone environment. Figure 3.11 shows good energy up to 300 hertz. Figure 3.12 is a composite of the different levels showing good P-wave and S-wave energy. This is very encouraging for future imaging at the tank scale.

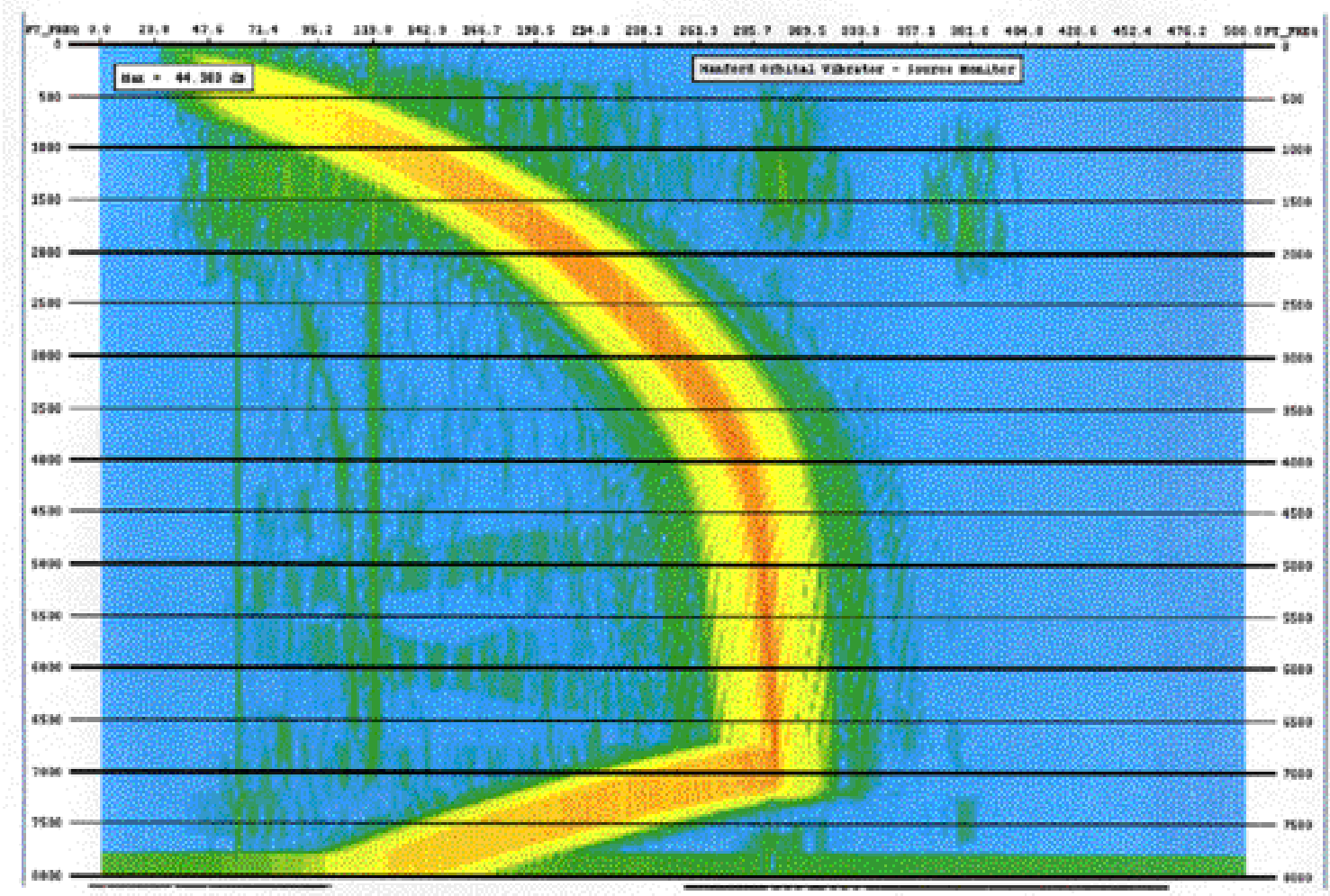

Figure 3.11. The Frequency Response as a Function of Time for the Seismic Source Used in the Large Offset Wells 


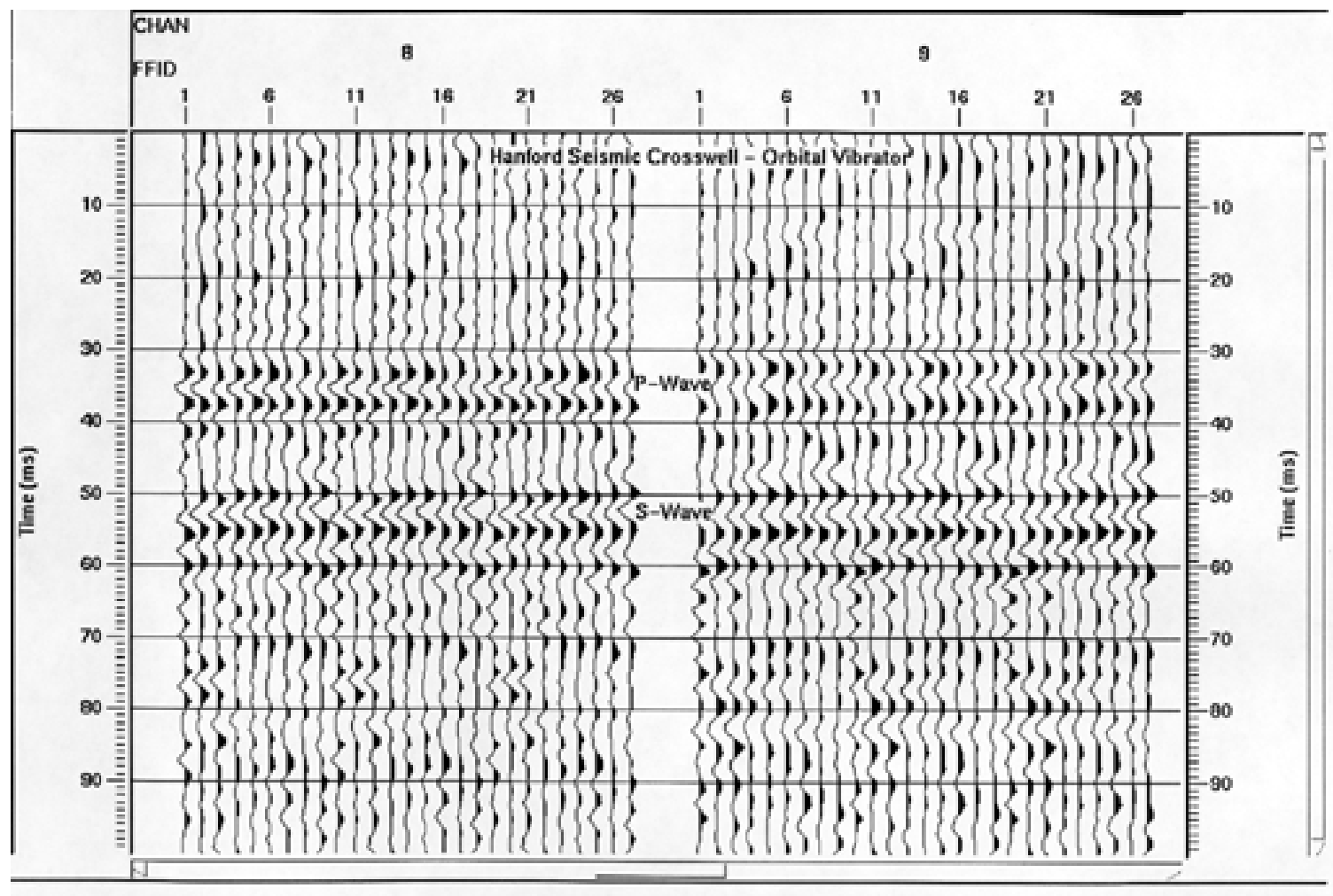

Figure 3.12. $\quad$ Example of Seismic Data at $19 \mathrm{~m}$ Through the Upper Vadose Zone Using a Seismic Source in the Range of 50 to 300 Hertz 


\subsection{Summary}

Overall, the radar and seismic results were excellent. At the time of design of the experiments, we did not know how well these two methods could penetrate or resolve the moisture content and structure. It appears that the radar could easily go up to 5, even $10 \mathrm{~m}$, between boreholes at $200 \mathrm{Mhz}$ and even father (up to $20 \mathrm{~m}$ ) at $50 \mathrm{Mhz}$. The seismic results indicate that at several hundred hertz, propagation of 20 to $30 \mathrm{~m}$, giving high resolution, is possible. One of the most important results, however, is that together the seismic and radar are complementary in their properties estimation, the radar being sensitive to changes in moisture content primarily, and the seismic being primarily sensitive to porosity. Taken in a time lapse sense, the radar can show the moisture-content changes to a high resolution, with the seismic showing high-resolution lithology. At the date of this writing, the two different data sets have not been merged or jointly interpreted with each other or other data sets; the potential for providing information on fluid flow through vadose-zone environments is very good. To date, the significant results are:

Radar: Delineated geological layers 0.25 to $3.5 \mathrm{~m}$ thick with 0.25 -m resolution

Delineated moisture movement and content with $0.25-\mathrm{m}$ resolution

Compared favorably with neutron probe measurements

Penetrated up to $20 \mathrm{~m}$.

Seismic: Delineated lithology at $0.25-\mathrm{m}$ resolution

Penetration over $20 \mathrm{~m}$, with a possibility of up to 30 or more meters.

Overall, the radar and seismic tomograms produce complimentary velocity fields and should provide complimentary information in determining hydologeological parameters. 


\subsection{References}

Freeman-Pollard, J. R., J. A. Caggiano, S. J. Trent, and ENSERCH. 1994. Engineering evaluation of the GAO-RCED-89-157, tank 241-T-106 vadose zone investigation. BHI-00061, Bechtel Hanford, Inc., Richland, Washington.

Lockheed Martin Hanford Company (LMHC). 1999. Preliminary Site-Specific SST Phase 1 RFI/CMS Work Plan Addendum for WMA S-SX. HNF-4380, Rev.0, Richland, Washington.

Myers, D. A., D. L. Parker, G. Gee, V. G. Johnson, G. V. Last, R. J. Serne, and D. J. Moak. 1998. Findings of the Extension Borehole, 41-09-39, 241-SX Tank Farm HNF-2885. Locheed Martin Hanford Corporation, Richland, Washington.

Peterson, J. E., B.N.P. Paulsson, and T. V. McEvilly. 1985. "Application of algebraic reconstruction techniques to crosshole seismic data," Geophysics, 50, 1566-1580.

Raymond, J. R., and E. G. Shdo. 1966. Characterization of subsurface contamination in the SX tank farm. BNWL-CC-701. Pacific Northwest Laboratory, Richland, Washington.

Rockhold, M. L., C. J. Murray, and M. J. Fayer. 1999. "Conditional simulation and upscaling of soil properties." In: Proceedings of the International Workshop on Characterization and Measurement of the Hydraulic Properties of Unsaturated Porous Media, pp. 1391-1401. M. Th. Van Genuchten, F. J. Leij and L. Wu (eds.). University of California, Riverside.

Topp, G. C., J. L. Davis, and A.P. Annan. 1980. "Electromagnetic determination of soil water content: Measurements in coaxial transmission lines," Water Resour. Res., 16, 574-582.

U. S. Department of Energy (DOE). 1998. Groundwater/Vadose Zone Integration Project Specification. DOE/RL-98-48, Richland, Washington. 